\title{
A Comparative Study of Issues Affecting ERP Implementation in Large Scale and Small Medium Scale Enterprises in India: A Pareto Approach
}

\author{
Parijat Upadhyay \\ International School of \\ Business \& Media \\ EN-22, Sector-V, Salt \\ Lake City, PIN-700091, \\ India
}

\author{
Rana Basu \\ West Bengal \\ University of \\ Technology \\ BF-142, Sector-I, \\ Salt Lake City, PIN- \\ 700064, India
}

\author{
Ritanjana Adhikary \\ West Bengal University \\ of Technology \\ BF-142, Sector-I, Salt \\ Lake City, PIN-700064, \\ India
}

\author{
Pranab K Dan \\ West Bengal University of \\ Technology \\ BF-142, Sector-I, Salt Lake \\ City, PIN-700064, India
}

\begin{abstract}
This paper attempts to explore and identify issues affecting Enterprise Resource Planning (ERP) implementation in context to Indian Small and Medium Enterprises (SMEs) and large enterprises. Issues which are considered more important for large scale enterprises may not be of equal importance for a small and medium scale enterprise and hence replicating the implementation experience which holds for large organizations will not a wise approach on the part of the implementation vendors targeting small scale enterprises. This paper attempts to highlight those specific issues where a different approach needs to be adopted. Pareto analysis has been applied to identify the issues for Indian SMEs and Large scale enterprises as available from the published literature. Also by doing comparative analysis between the identified issues for Indian large enterprises and SMEs four issues are proved to be crucial for SMEs in India but not for large enterprises such as proper system implementation strategy, clearly defined scope of implementation procedure, proper project planning and minimal customization of the system selected for implementation, because of some limitations faced by the Indian SMEs compared to large enterprises.
\end{abstract}

Keywords

Implementation, Enterprise Resource Planning, Small and Medium Enterprise, Pareto analysis, Large Scale Enterprise.

\section{INTRODUCTION}

Organizations of any magnitude have implemented or in the process of implementing Enterprise Resource Planning (ERP) in order to reap the benefits of integration and to remain competitive in the market. The dispersion of ERP systems in large and small-medium scale enterprises (SME) has been, by large, the most pertinent phenomenon since nineties in the sector of Information technology (IT). ERP is one of the novel solutions for both large and small and medium enterprises (SMEs) in order to improve productivity, efficiency and overall business performance. To achieve all of this, large and mediumsized organizations have realized the necessity to implement ERP software to achieve integration of business activities [1]. ERP applications constitute well - structured, reliable information technology (IT) backbones of fortune 500 companies worldwide [2].

Enterprise Resource Planning (ERP) built on the framework based on industry best practices, is a packaged software applications that can be configured to meet functional requirements of an organization, that integrate information from various disparate sources such as customers, supply chain, human resources, and financial accounting to make up the value chain of the enterprise allowing an organization to become significantly compliant and effective [3].

The Indian small and medium scale enterprises (SME) are eyeing the enterprise system solutions for their business in this changing business scenario. Although this shift has been gradual but it is picking up as Indian small and medium business (SMBs) are now competing globally and they need to gain a competitive edge to win amidst global competition. India's SME sector being vibrant, dynamic, flexible and productive entity containing about to some 12 million units that employing almost around 30 million people. Even though ERP systems were initially thought to run on large scale enterprises, SMEs are increasingly motivated to introduce ERP implementations [4]. A recent study finds SME companies focusing on growth strategies and customer services sometimes balancing between the two, but more often focusing exclusively on one or the other. As companies grow in size and improve performance, they are most likely to have invested in ERP system that will grow with them. As mid size companies grow, they must learn to operate in distributed environment and often experience proliferation of ERP and other enterprise applications. A number of publications have highlighted the failures and the frustrations that enterprises go through in implementing ERP systems. A Gartner group study was carried out in 1300 European and American companies and being found that $32 \%$ of ERP projects were delivered late and thus unable to achieve the true benefits of implementation.

Lured by seer magnitude of the SME sector in any country and particularly in India, many ERP vendors have been moving their attention toward SMEs [5] by providing simpler and cheaper solutions [6] from both the organizational and technological point of view, Pre- configured systems based on best practices at a fraction of cost originally required and promising implementation times of 60 days. In spite of such promises there is no general agreement on the effectiveness of such systems. As a result the current rate of ERP adoption in SMEs is still low.

Such a scenario raises some serious questions: Are SMEs informational needs as well as other issues are different from that of large organizations? Is it possible to identify a relationship between organizational climate and ERP adoption in companies of different size? Can certain factors or issues be identified that can be considered critical in context to SMEs but not for large organizations so that managers can focus on those key issues to make the implementation process smooth? This paper thus attempt to deal with such scenario. 


\section{LITERATURE REVIEW}

Enterprise Resource Planning (ERP) has widely used in developed countries all over the world to automate the deployment, streamline processes and for achieving process improvement and global competitiveness. But in recent years ERP vendors are trying to overcome the economic cultural and basic infrastructural barrier related to developing economy. For developing countries like India ERP system is in its early stage. It has been found that reasons like limit of capital, nonavailability of resources, poor management base, and absence of IT expertise are seriously affecting the implementation and adaptation of enterprise system in India and other similar Asian developing countries compared to the developed countries. However, there is not much difference in the events that would trigger an ERP implementation in SMEs as compared to large enterprises. SMEs have the same needs as large enterprises but face different challenges in view of their limited financial resources and capabilities[7]. SMEs either do not have sufficient resources or are not willing to commit significant portion of resources to complex ERP implementation process[8]. SMEs are more fragile than large companies [9], and the adoption of ERP is no longer limited to large scale enterprises [10]. According to Huin unless the differences between SME and large companies are clearly conceived, the ERP project will not reach to positive outcome [11]. So, deeper understanding of ERP implementation in SMEs needs to ensure a strong impact. Those fact holds that SME niche definitely require specific research and analysis other than previous investigations primarily targeting larger enterprises. This need has been understood so some researchers have started addressing specifically ERP implementation at SMEs. In this section some similar developing countries like India are selected to understand the characteristics of ERP in those countries and also to investigate the issues that are affecting the implementation of ERP system. But, the issues affecting implementation and impact of such enterprise system are different depending on the magnitude of organization as the business strategy and policy taken by Small and Medium scale enterprises (SMEs) are not the same as large organizations. So, the researchers here divided the review section according to the organization type.

\subsection{Review of Literature of Large scale Enterprise}

Huang and Palvia reviewed ERP implementation differences in developed and developing countries and concluded that economic status, government regulations, low IT maturity, firm size and lack of business process management experience as the major hindrance for firms in developing countries to reap the benefits from ERP investment [12].

Themistocleous et al. studied the adoption of Enterprise Application Integration in multinational organizations and has identified several factors for ES adoption which includes are: Benefits, Barriers, Costs, Internal pressures, External pressures, IT sophistication IT infrastructure, Support, Evaluation framework for the integration technology and packages [13].

Maria Divina et al. in their study presents an overview of ERP adoption in the Philippines by examining four Philippine business enterprises as case studies. The major question that their study addresses is: What organizational factors play a crucial role in the successful adoption of ERP in the Philippines? Specifically, what are the forces that either drive or restrain business enterprises from adopting ERP? The methodology adopted in this case study of four companiesthree from Cebu and one from Manila has been taken. From the detailed study the researchers analyzed and found that organizational culture being one of the factors responsible for successful ERP adoption. The factors that ensure successful ERP adoption among Philippine business enterprises are: management support; involvement of organizational members from all ranks in the planning and implementation stages; vendor support; and user education [14].

Zhang L. et al. classified the hypothesized factors into five categories: organizational environments, people characteristics, technical problems, ERP vendor commitment, and cultural impact. Organizational culture becomes a CSF here. It is emphasized that the researcher's study occurred in another country, China, whose culture is different from traditional ERP implementers. Most ERP vendors come from Europe and America. The difference of cultures between Western countries where the ERP systems are developed and China makes culture an important factor. Their empirical data analysis has shown that top management support, business process reengineering, effective project management, education and training, suitability of software and hardware, and data accuracy has a significant impact [15].

Pei Zhou- Sivunen in her research investigated the critical issues regarding ERP implementation in China. The study was based on case studies where Enterprise planning system like ERP was being implemented by two Chinese companies. The researcher used hypothesis in the study and found four issues that must be considered during ERP implementation are: mentality to work in team, proper education and training that must be given to the managers and employees before handling with ERP systems, personnel resource, BPR and software modification which should be used simultaneously in implementing ERP [16].

In a research study by Ashim Raj Singla and D P Goyal, attempt has been made to study the design and issues related to risk factors in implementation of ERP systems in two large manufacturing companies in India and ranked the ERP system risk factors which are as follows Implementation Risk Factors including No User involvement and training, Poor Project Management. And design risk factors includes Poor System Design, Poor Integration and technology planning [17].

Woo examined the ERP implementation experiences of a major Chinese enterprise named ElectronicCo from initial implementation problems to final success. The purpose was to provide Chinese enterprises with the knowledge about the CSFs in ERP implementation. From the study Woo presented six CSFs for this case company: top management, project team, project management, process change, education and training, and communication [18].

Almahdi.M.S.Ibrahim et al. in their research study presented a theoretical framework that has been developed which portrays the "soft" critical success factors in the process of implementing an ERP system. It was developed through a critical synthesis of the relevant literature. The results of the implementation framework, being tested in Libyan Oil company on the basis of case study. Soft ERP implementation factors were identified in the case study company which supported the key elements of the theoretical framework, however several unique soft implementation factors were also identified as mentioned previously. The theoretical framework is represented by three main sets of factors, namely strategy related factors (top management commitment, clear business vision, legacy systems), people related factors (training and education, users involvement, employee's attitude and project team) and organizational related factors (effective project management, process management, change management strategy, IT maturity, computer culture, empowerment, organizational culture, and communication) [19]. 
Muhammad Jamil Anjum et al., conducted a research survey in oil sector of Pakistan with the purpose to identify the critical success factors or issues in ERP implementation. The study concludes that critical success factors may keep the accomplishment on time, within resources, acceptable to the user, and so on if adequate training and Top management support is available within that firm [20].

In a similar developing countries like India Hany Abdelghaffar, Reem Hamdy and Abdel Azim , conducted a research study by collection of data, surveys and interviews with the major players of large organizations in Egyptian market and identified some critical issues or factors and classified into two (1) National /Environmental and (2) Organizational/Internal that would lead to positive outcome of ERP implementation success that includes are National or Environmental with Infrastructural facilities, Economy and economic growth of the country, Manufacturing, Regional, Government regulations. Organizational/Internal factors includes IT maturity, Computer culture, Business size, Management commitment, Experience of BPR [21].

Poonam Garg, identified and validate the critical success factors empirically for ensuring successful implementation of Enterprise Resource Planning (ERP) packages in context to retail industry in India. The identified issues or factors are: Top management commitment, Product selection, Project management, Team composition, Training and education [22].

\subsection{Review of Literature of Small and Medium Scale Enterprise (SME)}

According to Nah and Lau ten success factors have been identified by analyzing ten selective articles which are: ERP teamwork and composition, Top management support, Business plan and vision, Effective communication, Project management, Appropriate business and legacy system, Software development, Testing and troubleshooting, Effective - decision making, Effective training [23].

Pairin Katerattanakul et al. did a study that presents the issues related to ERP implementation in Korean small and medium manufacturing firms including pre-implementation activities, implementation experiences and ERP system configuration. From their study the researchers have identified that simple and standardized system should be always used. Also, gaining strategic advantage and ease of upgrading system were two important reasons for the responding firms to implement their ERP systems. For proper implementation experience it has been found that Korean SMEs use proper implementation strategy mostly "Mini big bang" approach [24].

In a research study by Jafari et al. after reviewing 28 articles identified ten success factors or issues in implementing ERP system in Malaysian companies which are: Support from top management, Clear goals and objectives, Communication, Effective project management, Business process engineering, Data accuracy and integrity, Suitability of software and hardware, Support from vendor, Education and training and User involvement [25].

P.T. Kale et al. on the basis of case studies of ERP implemented Indian SMEs and in-depth interviews with the ERP vendors and identified some issues in front of Indian SMEs. Some of them are: Awareness, Perception, Earlier implementations, implementation approach, cost, change management and limited resources. Furthermore, the researchers identified some of the factors that must be considered before starting Enterprise planning system implementation includes: infrastructure resource planning, proper education about ERP, human resource planning, support from top management, proper training facilities, commitment to release the right people for the implementation [26].

Ranzhe Jing et al. did a similar study for Chinese SMEs to identify the critical issues ensuring the successful implementation of ERP. The study identified four issues proved to be critical for successful ERP implementation are proper investment decision, participation of departments, proper support from vendor and providing training to the members of the organization [27].

Chen et al. did a study on the SMEs of Taiwan to investigate how the role of external consultant affects the ERP implementation project. The study explored that the involvement of external consultant along with management consultant in ERP implementation have significant impact on the ERP implementation practice. Also, the researchers have identified that the relationship between external consultants with SME managers highly affect the implementation project [28].

Upadhyay and Dan made an attempt to identify those factors that the organizations must keep in mind so as to ensure positive outcome of successful implementation of the enterprise planning systems . Based on the responses received from the respondents their study reveals that for ensuring successful implementation following issues are considered immense importance namely, clarity in goals and objectives behind implementation, adequacy of user training, competency in project implementation team, acceptance of changes brought about by implementation and adequate vendor support and participation of external consultants [29].

Further to this the researchers Upadhyay and Dan identified certain factors that have been found to be critical in context to implementation of IT projects. Seven factors have been identified that are found to be crucial are: Support from Top management, goals and objectives, user knowledge, project champion , project team competency, improve work efficiency, scalability \& scope and ERP importance. Out of this the first two are considered as most important [30].

Ali Noudoostbeni et al. assessed important success factors and failure factors in Malaysian SME companies and tries to recognize the effective ones. From the research the critical issues identified for successful implementation are proper team composition and effective training of users. Also, two issues identified responsible for the failure of the implementation are poor project planning and inappropriate training method [31]. Yuanqiang Xia et al. identified the critical success factors of ERP implementation in SMEs of China based on the analysis of the character of ERP marketing and nature of SMEs of China. Six critical success factors of Enterprise planning system implementation in SME of China are determined. The factors include: Top management support, Great competence project team, Right implementation scope, Management program change, Data accuracy, Education \& training. According to the researchers top management support is most important to ERP implement in SME of China, in which paternalism prevails. Also high power project team has tremendous significance in the situation of absence of IT engineer for SME. Education and training is helpful to successfully ERP implementing. Right implementation scope, data accuracy and management program change are the factors that can drive the project successfully in SMEs of China [32].

Vijaya Kumar et al. did a study to prioritize the issues affecting ERP system in medium scale fertilizer industry and the following factors were determined: adequate and correct data, training and testing, never run parallel system, conference room pilot, employee retention, customization, and clarity in management objective, external consultant dependency [33] 


\section{Methodology}

Based on the literature review certain issues and factors leading to successful ERP implementation and on the basis of frequency of citations made by several authors in context to both Large and small scale enterprises of similar developing countries like India 28 issues have been identified . However for identifying the key issues for both large and small scale enterprises Pareto analysis has been applied i.e. how many times the issues are mentioned by authors in the literature and arranged them in descending manner. And hence the key issues are extracted applying Pareto analysis.

\subsection{Data Collection procedure}

The data collection phase of the literature review has involved exhaustive search of many of the prime Management Information System (MIS) journals including that the researchers could access, but not limited to those that include: IEEE Journals, Information Systems Management journal, Business Process Management journal, Communications of ACM, International Journal of Computer Applications, Journal of Information Technology, International Journal of Production Research, Journal of Management Innovation System, International Journal of Computer Science and Information Security, Journal of Enterprise Information Management.

In addition to, the preceding journals, some conference papers, articles, were also accessed as well as , the following databases were searched like Emerald, Science Direct, Proquest, Ebscohost, Springer, J Stor etc.

\section{Data Analysis}

For identifying the key issues for large scale enterprises in the developing countries like India Pareto analysis has been applied. For this purpose, each issues mentioned by authors at least once in the literature is listed down with the frequency of each issues. From the frequency calculated for each issue the percentage contribution of each issue is computed, hence the cumulative percentage contribution of issues is calculated. It has been found that only 16 issues out of 28 are contributing $80 \%$ of the total percentage contribution. Hence, those 16 issues are regarded as the key issues being extracted from the review section in context to large scale enterprise in developing countries like India.

\begin{tabular}{|c|c|c|c|}
\hline $\begin{array}{l}\text { Issues mentioned } \\
\text { in the literature }\end{array}$ & $\begin{array}{l}\text { Number } \\
\text { of } \\
\text { instances } \\
\text { cited in } \\
\text { the } \\
\text { literature }\end{array}$ & $\begin{array}{l}\text { Percentage } \\
\text { contribution } \\
\text { of each issue }\end{array}$ & $\begin{array}{l}\text { Cumulative } \\
\text { percentage } \\
\text { of issues }\end{array}$ \\
\hline $\begin{array}{l}\text { 1. Education \& } \\
\text { training }\end{array}$ & 8 & $12.30 \%$ & $12.30 \%$ \\
\hline $\begin{array}{l}\text { 2. Top management } \\
\text { support }\end{array}$ & 7 & $10.76 \%$ & $23.06 \%$ \\
\hline $\begin{array}{l}\text { 3.Project } \\
\text { management }\end{array}$ & 5 & $7.69 \%$ & $30.75 \%$ \\
\hline 4. IT maturity & 4 & $6.15 \%$ & $36.9 \%$ \\
\hline 5. BPR & 4 & $6.15 \%$ & $43.05 \%$ \\
\hline 6.Team composition & 3 & $4.61 \%$ & $47.66 \%$ \\
\hline 7.User involvement & 3 & $4.61 \%$ & $52.27 \%$ \\
\hline $\begin{array}{l}8 . \quad \text { Infrastructural } \\
\text { facility }\end{array}$ & 2 & $3.07 \%$ & $55.34 \%$ \\
\hline 9. Economic status & 2 & $3.07 \%$ & $58.41 \%$ \\
\hline 10.Govt. regulation & 2 & $3.07 \%$ & $61.48 \%$ \\
\hline $\begin{array}{ll}11 . & \text { Computer } \\
\text { culture } & \\
\end{array}$ & 2 & $3.07 \%$ & $64.55 \%$ \\
\hline 12.Business size & 2 & $3.07 \%$ & $67.62 \%$ \\
\hline 13. Technology & 2 & $3.07 \%$ & $70.69 \%$ \\
\hline
\end{tabular}

\begin{tabular}{|c|c|c|c|}
\hline integration & & & \\
\hline $\begin{array}{l}\text { 14. Teamwork } \\
\text { mentality }\end{array}$ & 2 & $3.07 \%$ & $73.76 \%$ \\
\hline $\begin{array}{ll}15 . & \text { Personnel } \\
\text { resource } & \\
\end{array}$ & 2 & $3.07 \%$ & $76.83 \%$ \\
\hline $\begin{array}{l}16 . \quad \text { Change } \\
\text { management }\end{array}$ & 2 & $3.07 \%$ & $79.9 \%$ \\
\hline 17. Communication & 2 & $3.07 \%$ & $82.97 \%$ \\
\hline 18. Internal pressure & 1 & $1.53 \%$ & $84.5 \%$ \\
\hline 19. external pressure & 1 & $1.53 \%$ & $86.03 \%$ \\
\hline 20. Vendor support & 1 & $1.53 \%$ & $87.56 \%$ \\
\hline $\begin{array}{l}\text { 21. Clear business } \\
\text { vision }\end{array}$ & 1 & $1.53 \%$ & $89.09 \%$ \\
\hline 22. Legacy system & 1 & $1.53 \%$ & $90.62 \%$ \\
\hline $\begin{array}{l}23 . \quad \text { Process } \\
\text { management }\end{array}$ & 1 & $1.53 \%$ & $92.15 \%$ \\
\hline 24. Data accuracy & 1 & $1.53 \%$ & $93.68 \%$ \\
\hline $\begin{array}{ll}25 . & \text { Product } \\
\text { selection } & \\
\end{array}$ & 1 & $1.53 \%$ & $95.21 \%$ \\
\hline 26. System design & 1 & $1.53 \%$ & $96.74 \%$ \\
\hline $\begin{array}{l}\text { 27. Organizational } \\
\text { culture }\end{array}$ & 1 & $1.53 \%$ & $98.27 \%$ \\
\hline $\begin{array}{lr}28 . \quad \text { Suitability of } \\
\text { hardware } \\
\text { software }\end{array}$ & 1 & $1.53 \%$ & $99.89 \%$ \\
\hline TOTAL & 65 & $\begin{array}{l}100 \% \\
\text { (approx) }\end{array}$ & $\begin{array}{l}100 \% \\
\text { (approx) }\end{array}$ \\
\hline
\end{tabular}

Similarly, for small - medium scale enterprises 15 issues have been found which is contributing $80 \%$ of the total percentage contribution of issues. Hence, those 15 issues are identified as key issues or critical for small and medium scale enterprise for developing countries like India

Pareto Analysis (80-20 Rule) - Table 2

\begin{tabular}{|c|c|c|c|}
\hline $\begin{array}{l}\text { Issues mentioned in the } \\
\text { literature }\end{array}$ & $\begin{array}{l}\text { Number of } \\
\text { instances } \\
\text { cited in the } \\
\text { literature }\end{array}$ & $\begin{array}{l}\text { Percenta } \\
\text { ge } \\
\text { contribut } \\
\text { ion of } \\
\text { each issue }\end{array}$ & $\begin{array}{l}\text { Cumula } \\
\text { tive } \\
\text { percent } \\
\text { age of } \\
\text { issues }\end{array}$ \\
\hline 1. Education \& training & 7 & $10.76 \%$ & $10.76 \%$ \\
\hline $\begin{array}{l}\text { 2. Clearly defined goal and } \\
\text { scope } \\
\text { of implementation }\end{array}$ & 6 & $9.23 \%$ & $19.99 \%$ \\
\hline 3.Team composition & 5 & $7.69 \%$ & $27.68 \%$ \\
\hline 4. Top management support & 4 & $6.15 \%$ & $33.83 \%$ \\
\hline 5. Proper project planning & 4 & $6.15 \%$ & $39.98 \%$ \\
\hline 6.Minimal customization & 3 & $4.61 \%$ & $44.59 \%$ \\
\hline $\begin{array}{l}\text { 7.Proper implementation } \\
\text { strategy }\end{array}$ & 3 & $4.61 \%$ & $49.20 \%$ \\
\hline 8. Data accuracy & 3 & $4.61 \%$ & $53.81 \%$ \\
\hline 9. Role of external consultant & 3 & $4.61 \%$ & $58.42 \%$ \\
\hline 10.User involvement & 3 & $4.61 \%$ & $63.03 \%$ \\
\hline 11. Vendor support & 3 & $4.61 \%$ & $67.64 \%$ \\
\hline 12.BPR & 2 & $3.07 \%$ & $70.71 \%$ \\
\hline 13. Project management & 2 & $3.07 \%$ & $73.78 \%$ \\
\hline 14. Communication & 2 & $3.07 \%$ & $76.85 \%$ \\
\hline 15. Change management & 2 & $3.07 \%$ & $79.92 \%$ \\
\hline 16. Legacy system & 1 & $1.53 \%$ & $81.45 \%$ \\
\hline 17. Software development & 1 & $1.53 \%$ & $82.98 \%$ \\
\hline $\begin{array}{lll}18 . & \text { Testing } & \text { and } \\
\text { troubleshooting } & \end{array}$ & 1 & $1.53 \%$ & $84.51 \%$ \\
\hline 19. Ease of upgrading system & 1 & $1.53 \%$ & $86.04 \%$ \\
\hline $\begin{array}{l}\text { 20. Suitability of hardware and } \\
\text { software }\end{array}$ & 1 & $1.53 \%$ & $87.57 \%$ \\
\hline 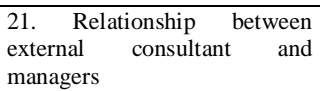 & 1 & $1.53 \%$ & $89.1 \%$ \\
\hline 22. Proper resource availability & 1 & $1.53 \%$ & $90.63 \%$ \\
\hline 23. User knowledge & 1 & $1.53 \%$ & $92.16 \%$ \\
\hline 24. Project champion & 1 & $1.53 \%$ & $93.69 \%$ \\
\hline 25. Improved work efficiency & 1 & $1.53 \%$ & $95.22 \%$ \\
\hline 26. ERP importance & 1 & $1.53 \%$ & $96.75 \%$ \\
\hline 27. Never run parallel system & 1 & $1.53 \%$ & $98.28 \%$ \\
\hline 28. Conference room pilot & 1 & $1.53 \%$ & $99.90 \%$ \\
\hline TOTAL & 65 & $\begin{array}{l}100 \% \\
\text { (approx) }\end{array}$ & $\begin{array}{l}100 \% \\
\text { (approx) }\end{array}$ \\
\hline
\end{tabular}




\section{FINDINGS AND DISCUSSION}

From the literature review and by applying Pareto analysis it has been found that 16 issues are identified as the critical issues responsible for ERP implementation success for large organizations and 15 issues for SMEs for developing countries in Indian context as those are contributing more than $80 \%$ of the total percentage contribution of issues. But some issues that are found to be critical for SMEs may not found to be critical in case of large organization. The objective of this paper is to find out those critical issues that have appeared exclusively for SMEs but not for large organizations. Those issues that are only critical to the SMEs are listed below:

- Clearly defined the goal and scope of implementation

- Proper project planning

- Proper implementation strategy

- Minimal customization

Clearly defined scope of implementation: It has been found from the past literature study that in the SMEs of the developing countries like China, India, Korea, Malaysia scope of implementation is one of the highly significant issue for the implementation of ERP. SMEs emphasis on the scope of implementation rather than large organizations as budget constraint is one of the limitation of those companies. Although ideally scope of implementation should be all inclusive; but as ERP implementation is a costly affair to implement all modules and functionalities of ERP is not a feasible decision for the SMEs. So, to implement the system successfully within the organization scope of implementation should be clearly defined to the implementation team.

Proper project planning: Ali Noudoostbeni et al. emphasizes on the project planning while doing a study for SMEs in Malaysia. In SMEs proper project planning is an important issue than large ones as in SMEs budget and time constraints are main the limitations found. If before starting the project the planning is not done thoroughly then the implementation project could be failed. So, it is the responsibility of the team members to do make proper plan of the project regarding the timeline, budget, each members "todo" list, milestones and critical paths [34].

Proper implementation strategy: There are different fundamental strategic approaches for implementing ERP system that organizations must decide to adopt based on their budget and timeline. Slevin \& Pinto first identified the vital role of implementation strategy [35]. Later Holland \& Light agreed with the fact that implementation strategy can be one of the most important strategic factors that can affect the whole implementation project greatly[36]. Although Phased rollout approach is considered as the more ambitious but the researchers believed that Big Bang approach can be the more suitable approach for SME's as it need much less amount of cost and time for implementation. Among the SMEs all over the world are recently trying to adopt "Vanilla approach" for successful implementation because of their budget and timeline constraints.

Minimal customization: Through a comprehensive review of the literature, Nah, in their study on SMEs in china concluded that minimum customization as one of the key issues in ERP implementation. Numerous studies of the critical issues for ERP implementation conclude that the preferable way to implement ERP software is software modification [23]. One estimate shows $20 \%$ of the processes in an organization cannot be modeled in an ERP system without customization. Minimal customization means using of code as given by vendors and to use much as possible to fit the organization needs even if to sacrifice functionality has been associated with successful implementation of ERP. It is to be kept in mind that organization would go for customization only when it is required.on qualitative work.

\section{LIMITATIONS AND CONCLUSION}

The findings of this paper are based. So quantitative techniques and surveys are required to receive a more general result. It would be more value achieved to combine the results of both qualitative and quantitative researches in the future. There is a scope to enhance to this study by taking different industries into consideration.

The above findings would reflects the perspectives of managers and implementors and holds significance for any organization in the small and medium scale sector who wishes to leverage the utility of integration of business processes by implementing an Enterprise Resource Planning system in their organization. SME's should thus focus on the issues like proper implementation strategy, clearly defined scope of implementation procedure, proper project planning and minimal customization, which are common for SMEs. The managers and users can be benefited from this study by identifying those key issues to make the implementation procedure smooth without any disruption. Further ERP vendors can take inputs from this study to change their implementation approach while targeting small scale enterprises.

\section{REFERENCES}

[1] Dalal, N.P., Kamath, M., Kolarik, W.J.,and Sivaraman,E.(2004). "Toward an integrated framework for modeling enterprise process", Communications of the ACM, 47(3), pp.83-87.

[2] Hofmann,P, (2008). "ERP is Dead, Long Live ERP", Internet Computing, IEEE, August 2008, 12(4), pp. 84-88

[3] Davenport, T.H. (1998). "Putting the Enterprise into the Enterprise System", Harvard Business Review, July/August 1998, 76(4), pp. 121-131

[4] Adam, F. and O'Doherty, P. (2000), “Lessons from enterprise resource planning implementations in Ireland towards smaller and shorter ERP projects", Journal of Information Technology, Vol. 15 No. 4, pp. 305-16.

[5] Gable, G. and Stewart, G. (1999), "SAP R/3 implementation issues for small to medium enterprises", paper presented at the Americas Conference on Information Systems, Milkwaukee, WI

[6] Kirchmer, M. (1998), "Business Process-Oriented Implementation of Standard Software: How to Achieve Competitive Advantage Quickly and Efficiently", Springer, New York, NY

[7] S.C.L. Koh, M. Simpson, J. Padmore, N. Dimitriadis and F. Misopoulos, (2006) "An exploratory study of enterprise resource planning adoption in Greek companies", Industrial Management \& Data Systems, Vol. 106 Iss: 7, pp.1033 - 1059

[8] Buonanno, G., Faverio, P., Pigni, F., Ravarini, A., Sciuto, D. and Tagliavini, M. (2005), "Factors affecting ERP system adoption: A comparative analysis between SMEs and large companies", Journal of Enterprise Information Management, Vol. 18 No. 4, pp. 384-426.

[9] Rao, S.S. (2000), "Enterprise resource planning: business needs and technologies", Industrial Management \& Data Systems, Vol. 100 No.2, pp.81-8. 
[10] Loh, T.C. and Koh, S.C.L. (2004), "Critical elements for a successful enterprise resource planning implementation in small-and medium-sized enterprises", International Journal of Production Research, Vol. 42 No. 17, pp. 343355.

[11] Huin, S.F. (2004), "Managing deployment of ERP systems in SMEs using multi-agents", International Journal of Project Management, Vol. 22 No. 6, pp. 511-17.

[12] Huang, Z. and Palvia, P. (2000), “ERP: perspectives from developed and developing countries", Proceedings Global Information Technology Management World Conference, Memphis, TN

[13] Themistocleous, M. (2002), "Enterprise Application Integration: An Emerging Technology for Integrating ERP and Supply Chains", European Conference on Information Systems, pp.1087-1096

[14] Maria Divina Gracia Z. Roldan, Antonio R. Zamora and Frederick D. Amores (2002),"Assessing enterprise Resource Planning (ERP) Adoption in the Philippines" Enterprise Resource Planning-Global Opportunities \& Challenges, Idea group publishing.

[15] Zhang L., Lee K.O.M., Zhang Z. and Banerjee P.( 2002), "Critical Success Factors of Enterprise Resource Planning Systems Implementations Success in China", IEEE Computer Society

[16] ZhouSivunen Pei (2005), ,Organizational Culture Impact in ERP Implementation in China". Available from http://www.pafis.shh.fi/graduates/index.html

[17] Ashim Raj Singla and D P Goyal (2005). "Managing risk factors in design and implementation of ERP systems (An empirical investigation of the Indian industry)", Journal of Advances in Management Research, IIT Delhi Vol. 3, No. 1

[18] Woo, H. S. (2007), "Critical success factors for implementing ERP: the case of a Chinese electronics manufacturer", Journal of Manufacturing Technology Management, 18, Issue 4, pp. $431-442$

[19] Almahdi .M. S. Ibrahim, John. M. Sharp and Aris. A. Syntetos (2008)," A Framework for the implementation of ERP to improve business performance: A case study", European and Mediterranean Conference on Information Systems May 25-26

[20] Muhammad Jamil Anjum, Shaheed Zulfikar Ali Bhutto and Ijaz-Ur-Rehman (2010), "Critical Success Factors OF ERP Implementation in Pakistan", http://www.iqraisb.edu.pk/icbt/Proceeding_ICBTE_2010/P roceeding\%20Papers/136.pdf

[21] Hany Abdelghaffar, Reem Hamdy and Abdel Azim (2010), "Significant Factors Influencing ERP Implementation in Large Organizations: Evidence from Egypt", European, Mediterranean \& Middle Eastern Conference on Information Systems 2010, Abu Dhabi, Dubai

[22] Poonam Garg (2010), Critical Success factors for Enterprise Resource Planning implementation in Indian Retail Industry: An Exploratory study, (IJCSIS) International Journal of Computer Science and Information Security, Vol. 8, No. 2, 2010
[23] Nah, F. F. and Lau, J. L. (2001). Critical success factors for successful implementation of enterprsie systems. Business Process Management, 285-296.

[24] Pairin Katerattanakul, Soongoo Hong and Jinyoul Lee (2006), Enterprise resource planning survey of Korean manufacturing firms, Management Research News Vol. 29 No. 12 , pp. 820-837

[25] Jafari, S. M., Osman, M. R., Yusuf, R. M., and Tang, S. H. (2006). ERP systems implementation in Malaysia: theimportance of critical success factors. Engineering and Technology, 3, 125-131.

[26] P. T. Kale, S. S. Banwait and S. C. Laroiya (2007), "Enterprise Resource Planning Implementation in Indian SMEs: Issues and Challenges" , National Institute of Technical Teachers' Training and Research, www.csisigegov.org/critical_pdf/27_242-248.pdf

[27] Ranzhe Jing et al (2007), "A Study on Critical Success Factors in ERP Systems implementation", 1-4244-08857/07/ (C2007 IEEE.

[28] Chen, R., Sun, C., Helms, M.M.and Jih, W. (2008), "Role negotiation and interaction: an exploratory case study of the impact of management consultants on ERP system implementation in SMEs in Taiwan", Information Systems Management, Vol. 25 No.2, pp.159-73

[29] Parijat Upadhyay and Pranab K Dan (2008), “An explorative study to identify the Critical Success Factors for ERP implementation in Indian small and medium scale enterprises" -978-0-7695-3513-5/08 IEEE

[30] Parijat Upadhyay and Pranab K. Dan (2009), "ERP in Indian SME's: A Post Implementation Study of the Underlying Critical Success Factors", International Journal of Management Innovation System ISSN 19431384, Vol. 1, No. 2: E1

[31] Ali Noudoostbenil and Norizan Mohd Yasin (2009), "To investigate the Success and Failure Factors of ERP implementation within Malaysian Small and Medium Enterprises" 978-0-7695-3595-1/09 IEEE

[32] Yuanqiang Xia, Peter Lok and Song Yang (2009), "The ERP implementation of SME in China", 6th International Conference on Service Systems and Service Management, pp. $135-140$

[33] Vijaya Kumar et al. (2010), "Application of Analytical Hierarchy Process to Prioritize the Factors Affecting ERP Implementation", International Journal of Computer Applications (0975 - 8887) Volume 2 - No.2.

[34] Ali Noudoostbeni1 and Norizan Mohd Yasin (2009), To investigate the Success and Failure Factors of ERP implementation within Malaysian Small and Medium Enterprises" 978-0-7695-3595-1/09 IEEE

[35] Slevin and Pinto (1987), "Critical factors in successful project implementation", IEEE Transactions on Engineering Management, EM-34

[36] Holland, C. and Light, B. (1999), “A critical success factors model for ERP implementation", IEEE, Software, Vol. 16, p. 30. 